\title{
Some Observations on the Employment of Lepers, Out-patients and others, during and after Treatment.
}

\author{
R. S. Donaldson.
}

" DAITH, oil and work, but the greatest of these is $\checkmark$ work." So wrote Dr. R. M. Wilson, of Korea, in 1 his excellent article on "Industrial Therapy in Leprosy," in the LEPROSY REVIEw for January, 1930. I do not intend in this article going into the question of work for lepers in leper colonies-I refer readers to the article I have mentioned for that-but if every leper colony should be " an industrial therapeutic institution," how fortunate is the man who can take his treatment and still carry on with his own work without becoming an inmate of a leper hospital.

With the advent of out-patient treatment for the noninfectious leper, and the fact that there will no doubt be a great increase in the number of out-patient clinics in the near future, the question of employment of lepers during their treatment, the duration of their treatment and their after-care, are things which will require attention.

I have found that a great number of our in-patients who voluntarily left their employment to take treatment in the Settlement found great difficulty in getting back their jobs after treatment. Many of them, in fact, never got them back, in spite of their having certificates stating that they were no longer a danger to others with whom they may come in contact.

We want to encourage employees not to hide their disease, but this very fear of losing their employment makes them hide it until they are advanced cases. Government servants in Madras Presidency-constables, for instanceare encouraged to report any suspicious signs or symptoms of leprosy on their bodies by being promised leave with pay during treatment, provided they take such treatment at a recognised treatment centre for leprosy and produce a satisfactory certificate from the Medical Officer of the institution. The consequence is that we have almost a sufficient number of constables taking treatment at the Settlement to form a police force. How common the disease must be in India. When there is no need to hide the disease because of the fear of loss of employment, how much better it is for everyone- 
patient and doctor-getting the disease diagnosed early, and having it treated.

But what of the general body of employers? Are they encouraging their employees not to hide their disease, but to come forward and get it treated early? In many instances they are not. If difficulty were experienced before in getting employers to grant leave to their workers suffering from leprosy so as to obtain treatment in a leper hospital, it is not going to be any easier to get them to allow certain of their employees to continue their work during treatment.

After opening the out-patient clinic at Chingleput Leper Settlement about four years ago, I discovered that many employers would not allow their employees to continue with their work while undergoing treatment, though every assurance had been given that the cases were not infectious, nor would they give them any guarantee of employment after completion of treatment. These people had therefore either to become inmates of the Settlement, where they had proper food and attention, or else become out-patients with no work and no pay, and therefore difficulty in procuring the wherewithal to live. Such cases provide a very strong argument for hospitals being available even for certain noninfectious cases. There are always going to be cases without the means of getting proper food and care during treatment, and these to my mind do not seem to be very fit subjects for antileprotic treatment.

If out-patient treatment has to be the order of the day for non-infectious cases, something will have to be done to convince employers that all types of leprosy are not the same. The very name of leper is of ten enough to have a man dismissed, no matter what arguments are brought to bear against it. Even if you succeed in convincing him he wants an idea as to how long the treatment is going to take, and whether the patient during treatment and after being declared symptom-free, or whatever declaration is made, is going to remain as fit for his work as he was before. He wants a prognosis. These are quite legitimate things for him to know. I therefore think that all those who are treating leprosy to-day will have to be very careful if the treatment is not going to be brought into disrepute. We must remember that it is very easy to bring new forms of treatment into disrepute, but it is very hard to establish them so strongly that everyone will have confidence in them. For this reason, therefore, I would ask that the questions of prognosis and the very careful decision as to which are infectious and which are non-infectious should not be lightly passed over. Now is 
the time to gain the confidence of the public as to the effectiveness of modern methods of treatment, and careful diagnosis as to the type and also the stage and phase of the disease, careful prognosis, and greater care in finally signing off cases, never were more essential.

Type, Stage, Phase, etc.

A thorough understanding of your case classification is all-important. For a very good and concise account of the types, stages and phases of leprosy I would strongly refer readers to Dr. E. Muir's booklet on "Leprosy, Diagnosis, Treatment and Prevention," 5th edn. (Ch. i, Sects. 6 and 7), issued by the Indian Council of the British Empire Leprosy Relief Association. A study of the sections I have referred to will be of great help in classifying a case of leprosy.

It is absolutely necessary to make a clear distinction between infectious and non-infectious cases. A great number, perhaps the majority, of cases of leprosy in lndia at any one time are non-infectious cases. Many are not infectious to begin with, though due to their poor resistance, they become infectious later on. Many of these infectious cases again become non-infectious towards the end of the disease. The criterion of whether a case is infectious or not must be whether it is possible for a specially trained physician to discover bacilli upon careful bacteriological examination. As the infection is not on the surface of the body, but under the epithelium, when it exists, it is not too much to assume that cases in which careful examination of the deeper parts of the skin or mucous membrane fails to show any Hansen's bacilli cannot be regarded as a danger to others. Leprosy differs from tuberculosis in not producing disease of the bowel, and Hansen's bacilli are not therefore found in the fæces. They are also practically never found in the urine. With modern treatment of early diagnosed cases it should be possible almost always to arrest and gradually get rid of all signs of the disease before cases become infectious.

Non-infectious cases should only be allowed to carry on their trades on condition that they place themselves under specially trained medical supervision in a recognised centre both for treatment and inspection. This will ensure that they do not drift on into the infectious stage after being passed as non-infectious cases.

Duration of Treatment and After-care.

Treatment should be carried on for a varying period 
in different cases, but on an average for six months after all active signs have disappeared. In Madras, government servants before being discharged from treatment must satisfy three conditions, and these must be shown on their certificates signed by the Medical Officer of the recognised treatment centre. They are as follows :

(1) No new lesions have appeared for at least six months.

(2) Old lesions have shown no tendency to spread or other form of activity over a period of six months.

(3) Repeated bacteriological examinations of skin, mucous membranes and lymph nodes on puncture have proved negative over a period of six months.

It would be wise, I think, to see that every patient has such a certificate in his possession before he stops treatment, and employers should demand to see them.

Then, again, it must be insisted on that patients return at stated intervals for examination. They ought to return at least every three months for a period of two years. Even then some bacilli may be lying latent in the body, and a lowered resistance at some future time may allow them to act. I consider therefore that patients should carry on with some kind of treatment during the two years, because, from a therapeutic point of view the six months' freedom from activity of the disease noted above in the conditions for discharge should be two years. I have noticed on several occasions that patients who left the Settlement before completing their treatment have returned for readmission after a month or two looking better than when they left. They had continued to improve in the interval. It would appear that the hydnocarpus group of drugs which had been used had a cumulative power, and was stored up in the body, and continued to act after injections had been stopped. I would therefore advise that patients after discharge should return for one month's treatment four times a year during their two years of observation. This might have the effect of preventing any return of active disease and destroy any latent bacilli which may be present.

\section{Prognosis.}

I do not intend going into the question of prognosis. All those who are working on the subject of leprosy know how different it is to give a prognosis in leprosy as compared with other diseases. That is why I think it is important with modern methods of treatment to give as careful a prognosis as possible. In making a prognosis, remember 
that it depends on several things, among them being the stage of the disease, the duration of the disease before the patient came for treatment, the presence of concomitant diseases and the type of treatment given. It is only after careful consideration of all these that one can give a candid opinion of the case and an idea as to the possible time the patient will require active treatment. An article on the subject of prognosis by Dr. R. G. Cochrane appeared in LEPROSY REviEw for January, 1930, and I refer readers to it as well as to the section on prognosis in Muir's booklet already referred to.

We have occasionally had cases of all types, stages and phases of the disease brought or sent to us, who certainly were not then, and never would be, able to carry on their duties as before. We must be candid about these cases to employers, and tell them that the outlook is not good. Should we consider that a case can be very much benefited, though it may take two or even three years of active treatment, then it is a matter for the employer to consider whether he can grant leave with pay or part of it, or only leave with a promise of re-employment after treatment, to such patients, for so long a period. For the sake of other patients in the future, however, he ought to know exactly what the position is, and not be made to think that it will only be a matter of a few months before his employee will be quite fit again. Whether the case be non-infectious or infectious, whether he be treated as an out-patient or as an in-patient makes no difference to the care required in classifying and advising so as to give the employer and the patient himself a true idea of the situation.

Cases.

In conclusion, may I quote two cases which I have met with, and which show the great difficulty and the care necessary in making decisions in certain instances.

A teacher came to me for examination, and I diagnosed him as suffering from early nerve leprosy. He was bacteriologically negative. I stated that he could come to me as an out-patient for treatment and carry on with his duties. On reporting the matter to his superiors he was served with a dismissal notice, although he had been teaching in the school for many years. I took the matter up, and after some discussion he was allowed to continue his work while attending the hospital as an out-patient. Here is an instance of a person suffering from non-infectious leprosy and continuing his duties while undergoing treatment, which creates a little 
doubt even in the mind of a doctor, chiefly because the man was engaged in teaching young children. Are we so sure of our ground as regards the non-infectivity of bacteriologically negative cases as to entitle us to allow teachers to continue teaching in schools while they are under antileprotic treatment?

The second case was that of an Anglo-Indian woman employed as a children's nurse. She was employed by Europeans. On a visit to England with her employer the ring and little fingers of her left hand began to bend, and she lost sensation in these two fingers. She was diagnosed as a case of syringomyelia, and demonstrated as such to students. Later, a dermatologist diagnosed leprosy, and advised her to return to India, as she would get better treatment there. Being a native of Madras district, she came to Chingleput, and I at once saw that she was a case of mixed leprosy, and was very infectious. Her nasal septum was badly ulcerated, and smears contained abundance of Hansen's bacilli. She had had occasional nose bleeding for two or three years. Her cheeks were also slightly infiltrated, and snips from a patch on the back were positive. She had a typical main-engriffe. After treating her for two years, I declared her a "disease arrested" case, and asked her to return periodically for a period of two years for observation. She asked me when she could resume her duties as a children's nurse, and I told her that I really did not consider it was right of her to think of continuing as a children's nurse under the circumstances.

I do not know whether I was justified in doing what I did in these two cases, but I quote them as exemplifying the necessity for careful consideration in deciding (1) whether a patient should continue his employment during treatment even though he be a non-infectious case, and (2) whether a patient, especially a highly infectious one, should return to his or her original employment after treatment.

There are certain trades and occupations in which it is undesirable that a patient during treatment for leprosy should be employed even if he is a non-infectious case. These are such trades as would interfere with or impede his own general health, and then there is the question of the advisability of his working among certain others, such as children, as noted in the case of the teacher.

The question as to the resumption of the same employment after treatment as was engaged in before treatment, especially if the case was highly infectious, also resolves itself into two, that from the point of view of the general 
health of the patient in preventing a return of the disease, and consideration for others.

I may say here that I do not consider that any case of leprosy of the infectious type, i.e., bacteriologically positive, no matter how few acid-fast bacilli can be found, should be treated as an out-patient, unless it is found impossible to find accommodation for him in a leper hospital. If it is not possible to get him into a hospital, he should not be allowed to work with others until he has been rendered bacteriologically negative. 